\title{
Prevalence of Xerostomia and its Related Factors in Patients Referred to Zahedan Dental School in Iran
}

\author{
Masoomeh Shirzaiy,,$^{1 *}$ and Fathemeh Bagheri ${ }^{2}$ \\ ${ }^{1}$ Oral and Dental Disease Research Center, Zahedan University of Medical Sciences, Zahedan, IR Iran \\ ${ }^{2}$ Oral and Dental Disease Research Center, Qom University of Medical Sciences, Qom, IR Iran \\ "Corresponding author: Masoomeh Shirzaiy, Oral and Dental Disease Research Center, Zahedan University of Medical Sciences, Zahedan, IR Iran. Tel: +98-9153498265, Fax: \\ +98-5412414003. E-mail: shirzaiy@gmail.com
}

Received 2015 December 31; Revised 2016 January 15; Accepted 2016 February 15.

\begin{abstract}
Background: Xerostomia is a condition in which salivary secretion is reduced for various reasons. Some complications of the disease include tooth decay, burning mouth and atrophic mucosa.

Objectives: This study was conducted to determine the prevalence of xerostomia and its related factors in patients referred to Zahedan dental school in Zahedan city, Iran.

Patients and Methods: In this descriptive-analytical study, the questionnaires were completed for 400 patients (aged 20 - 71 years) referred to Zahedan dental school in 2007. They were examined by an oral medicine specialist and the criteria of xerostomia diagnosis included fissuring lip, pale and atrophic mucosa, smooth, red and depapillated tongue, complaining sticking lips together, cervical and top of teeth cusps caries and sticking tongue blade to mucosa. The presence of three criteria for at least a week and unstimulated salivary flow rate $<0.1$ were necessary to confirm the disease. The data were analyzed using the chi-square test by the SPSS software version 16 .

Results: From a total of 400 patients, 211 cases (52.8\%) were female and 189 (47.2\%) were male, of which 143 persons (35.8\%) affected by xerostomia. The prevalence of xerostomia was higher in people older than 51 years (59.4\%). Also, women (39.8\%), antihistamine (90.9\%) and bronchodilator (83.3\%) drugs users, patients with neural (\%78.3) and psychotic (77.2\%) disorders, cigarette smoking (52.2\%) and hookah (61.3\%) users had experienced more xerostomia.

Conclusions: Xerostomia is more common in females and older people. According to the results of the present study, it seems that the factors such as systemic disease involvement, taking medications, age and gender may be associated with xerostomia
\end{abstract}

Keywords: Xerostomia, Saliva, Related Factor

\section{Background}

Xerostomia or dry mouth is a condition in which salivary secretion is not enough (1). Saliva is a complex and important body fluid that plays a significant role in the protection and lubrication of oral mucosa, digestion, taste sensation remineralization of teeth, phonation, clearance and buffering action and antibacterial activity. Therefore, it is critical for maintaining and protection of oral and dental health and is necessary for the integrity of the oral tissues $(2,3)$. Salivary gland hypo-function (objective evidence of low saliva secretion) and the subjective complaint of dry mouth can have an important effect on many aspects of oral function and general health; thus, they can cause a significant decline in the quality of life $(3,4)$. Common causes of dry mouth included the salivary gland atrophy, taking antidepressant and antihypertensive medications, history of radiation therapy in head and neck region, chemotherapy, the Sjogren's syndrome, smoking and affecting by diseases such as diabetes and hypertension (1, $5-8$ ). The prevalence of xerostomia varies between $25 \%$ to
$40 \%$ and it is more common in women and elderly persons (1, 5-7). More than 1500 drugs can cause xerostomia (7).

In some studies, the incidence of xerostomia and related factors was evaluated (3). Thomson's study showed that (2006) taking medications such as antidepressants, iron and analgesics can cause xerostomia. In this study, 10\% of the participants were affected by xerostomia and there was no significant difference in the prevalence of xerostomia between men and women (9).

In Pajukoski's study (2001) (10), 63\% of hospitalized patients complained of xerostomia and this condition was more common among women. In this study, a decreased salivary flow rate and respiratory disease were the most important causes of xerostomia.

In Salako et al. study (2005) (11), a total of $20 \%$ of Saudian adults were affected by xerostomia. The condition was more common in those who taking medication and old people.

In Pujol et al. study (1998) (12), 7.9\% of the Spanish adults involved with xerostomia and systemic medication 
as well as age were directly correlated with dry mouth.

The most important complications of dry mouth included tooth decay, halitosis, burning sensation and atrophy of mucosa and impaired swallowing and speaking (7).

Orellana et al. (2006) (13) showed that $86.8 \%$ of elderly Scandinavian people had xerostomia. They complained of difficulty in chewing and swallowing and used antidepressant and antihypertensive medications more than other (healthy people without dry mouth).

One of the most important side effects of taking antidepressants and complications of psychological disorders is dry mouth. Baharvand and Hemmati (14) assessed elderly residents of sanitariums older than 65 years in Tehran and found that dry mouth is more common in people with depression, and sleep disorders and sedative users. In this study $34 \%$ of the patients had xerostomia and the prevalence of this condition in women was higher than in men.

Several drugs are available that improve a salivary flow rate, including cevimeline, pilocarpine and artificial saliva which can be effective in increasing a salivary flow rate and elimination of xerostomia symptoms (7).

Xerostomia is a condition that occurs frequently in elderly population and can be associated with multiple complications. Also, the quality of life can be reduced by xerostomia (3).

To prevent these complications, it is necessary that the incidence of xerostomia and its related factors be detected. Few studies have been performed in this field (3).

\section{Objectives}

Considering to the importance, psychosocial and physical effects of xerostomia, this study aimed to investigate the prevalence of xerostomia and its related factors in patients attending to Zahedan dental school in Iran.

\section{Patients and Methods}

In this descriptive-analytical study, 400 patients referred to the oral medicine department in Zahedan dental school, Iran, in 2007, were assessed for xerostomia through the simple sampling method. The sample size was calculated to be 384 persons by considering $\mathrm{P}=20 \%$ and the confidence level 95\%. To minimize the errors of the survey, the sample size was determined 400 persons (5\% more than which was calculated through formula).

A written informed consent was obtained from each patient. The patients with a history of radiation therapy in head and neck region, those affected by the Sjogren's syndrome or other connective tissue diseases and also pregnant women were excluded from the study. In case of propensity, a questionnaire was completed for each participant and his/her individual characteristics including age, sex, systemic disease involvement, tobacco use and current systemic medication were recorded. In this study, unstimulated saliva was collected by the spitting method (15) during 9 - 11 AM. Participants were asked to avoid eating, drinking, and brushing 90 minutes before sampling. In this method, the patient must sit down and be comfortable while collecting the saliva. The patients drained the saliva in the tube by spitting 1-2 times every 1 minute for 5 minutes (15). All of the subjects were examined by an oral medicine specialist using a mirror and xerostomia was diagnosed according to the following criteria (9):

1- Lip dryness which was evident considering crack, sloughing and lip stickiness together,

2- Crack, atrophy and pale color of mucosa,

3- Stickiness of instrument to mucosa,

4- Tongue dryness (smooth, red and depapillated appearance of tongue),

5- Decay of the cervical region and cusp tips of the teeth.

In presence of three of these criteria (9) and the unstimulated saliva flow rate $<0.1$ (7), xerostomia diagnosis was confirmed. Finally, all data were analyzed using Chisquare test by SPSS software version 16 (SPSS Inc, Chicago, Illinois, USA).

\section{Results}

From a total of 400 patients, aged 20 - 71 years, 211 cases (52.8\%) were women and 189 (47.2\%) were men. A total of 84 females (39.8\%) and 59 males (31.2\%) had xerostomia. Dry mouth was more common in females than in males. There was a significant association between gender and xerosto$\operatorname{mia}(\mathrm{P}=0.04)$.

Patients were divided into three groups according to the age. One-hundred and eighty-one patients (45.2\%) were under 30 years, 155 (38.8\%) in the age range of 31 - 50 years and 64 cases (16\%) were older than 51 years.

The mean age of the participants was $35 \pm 8.7$ years. Xerostomia was more common among patients older than 51 years and there was a statistically significant association between xerostomia and age so that dry mouth was increased with increasing age $(\mathrm{P}<0.001)$ (Figure 1$)$.

Forty out of 189 studied women were menopaused and the prevalence of xerostomia was $42.5 \%$ (17 persons) among them. While $39.2 \%$ of the nonmenopaused women (67 persons) had xerostomia. There was a significant difference in the prevalence of xerostomia between menopausal and nonmenopausal women $(\mathrm{P}=0.003)$.

In the studied population, the prevalence rates of xerostomia among tobacco users were as follows: $61.3 \%$ in 


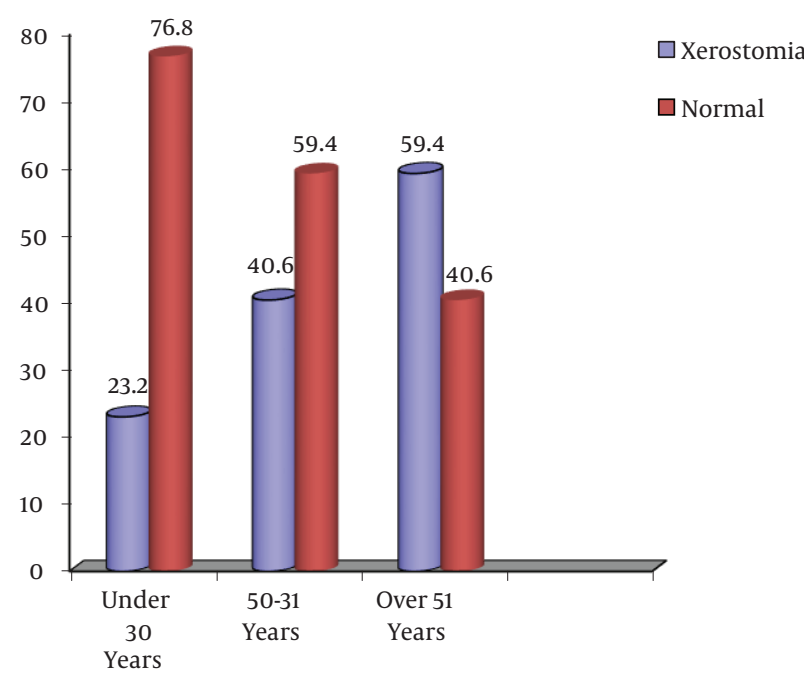

Figure 1. Frequency of Xerostomia According to the Age in Studied Population

hookah users, $52.2 \%$ in smokers, $32.2 \%$ in snuff users and $33.3 \%$ in opium takers.

Table 1 shows consumption of systemic medications in patients with xerostomia. The prevalence of xerostomia in drug users was $63.6 \%$. Also, $21.9 \%$ of the subjects used no systemic drugs. There was a significant association between xerostomia and taking medications $(\mathrm{P}<0.001)$.

Table 1. Comparison of Taking Medications in Patients With Xerostomia and Healthy Individuals in Studied Population ${ }^{\mathrm{a}}$

\begin{tabular}{lcc}
\hline Xerostomia Taking Medications & Yes & No \\
\hline Sedative, antidepressant & $19(73.1)$ & $7(26.9)$ \\
\hline diuretic & $19(73.1)$ & $7(26.9)$ \\
\hline Antihistamines & $10(90.9)$ & $1(9.1)$ \\
\hline Antihyperthyroidism & $9(64.3)$ & $5(35.7)$ \\
\hline Hypoglycemic and Lipid-lowering agents & $14(70)$ & $6(30)$ \\
\hline Bronchodilator & $10(83.3)$ & $2(16.7)$ \\
\hline Antibiotic & $2(16.7)$ & $10(83.3)$ \\
\hline Analgesics & $1(9.1)$ & $10(90.9)$ \\
\hline Total & $84(63.6)$ & $48(36.4)$ \\
\hline P value & $\mathrm{P}<0.001$ & $\mathrm{P}<0.001$ \\
\hline
\end{tabular}

${ }^{\mathrm{a}}$ Values are expressed as No.(\%).

${ }^{\mathrm{b}}$ Chi-square test.

In this study, $50 \%$ of the subjects with a history of mouth breathing were affected by xerostomia.

Systemic disease involvement in the studied population has shown in table 2.The Prevalence of xerostomia was $72 \%$ in this group and $28 \%$ in healthy persons. There was a significant difference between the two groups $(\mathrm{P}<0.001)$.

Table 2. Comparison of Systemic Diseases in Patients With Xerostomia and Healthy Individuals in Studied Population $^{\mathrm{a}}$

\begin{tabular}{lcc}
\hline Xerostomia Systemic Diseases & Yes & No \\
\hline $\begin{array}{l}\text { Psychotic depression-dementia, sleep } \\
\text { disorders, anxiety }\end{array}$ & $34(77.2)$ & $10(22.8)$ \\
$\begin{array}{l}\text { Endocrinediabetes-hypothyroidism- } \\
\text { hyperthyroidism }\end{array}$ & $17(58.6)$ & $12(41.4)$ \\
$\begin{array}{l}\text { Respiratory asthma-emphysema-chronic } \\
\text { bronchitis-mouth breathing }\end{array}$ & $9(64.3)$ & $5(35.7)$ \\
$\begin{array}{l}\text { cardiovascular disease Angina pectoris, } \\
\text { hypertension-heart failure }\end{array}$ & $22(75.9)$ & $7(24.1)$ \\
\hline $\begin{array}{l}\text { Neural Parkinson-history of cerebrovascular } \\
\text { disease }\end{array}$ & $18(78.3)$ & $5(21.7)$ \\
\hline $\begin{array}{l}\text { Total } \\
\text { Pvalue }\end{array}$ & $100(72)$ & $39(28)$ \\
\hline $\begin{array}{l}{ }^{a} \text { Values are expressed as No.(\%). } \\
\text { b Chi-square test. }\end{array}$ & $\mathrm{P}<0.001$ & $\mathrm{P}<0.001$ \\
\hline
\end{tabular}

\section{Discussion}

The present study was conducted to evaluate the prevalence of xerostomia and its related factors in patients referred to Zahedan dental school. The prevalence of xerostomia in the studied population was $35.8 \%$. The results of a systematic review determined that the prevalence of dry mouth in 13 selected articles ranged from $0.9 \%$ to $64.8 \%$ (3, 13). Rad et al. (2013, Kerman) (3) reported that the prevalence of xerostomia in 1010 Kermanian subjects in Iran was $55 \%$.They evaluated subjective xerostomia while we investigated objective xerostomia. The result of the Sreebny et al. (16) study was in accordance with that of the present study and the prevalence of xerostomia was $40 \%$. Unlike the present study, other researches on the prevalence of oral dryness in general population showed that it can be detected in up to $46 \%$ of the people (17).

Wilczynska-Borawska et al. (18) found that nearly $30 \%$ of the old people experience some degrees of xerostomia. Similarly in some studies, medication, age and gender have been generally enforced as the most common causes of oral dryness (17-19).

The prevalence of xerostomia in Pajukoski et al. study (10) was higher (63\%) than that reported in our study. Also, Kaur et al. (2016) (20), unlike the present study, reported that the prevalence of xerostomia in an adult population in psychiatric clinic was 60\%. In Pajukoski et al. (10) study hospitalized patients and in Kaur et al. study (20) psychologic patients were evaluated while in the present study the prevalence of xerostomia in dental patients was assessed. 
Typically, the studied groups in Pajukoski et al. (10) and Kaur et al. (20) studies had more oral and systemic problems, which predispose them to xerostomia. The prevalence of xerostomia in Thomson et al. (9) study was lower than that of the current study (10\%). This difference can be due to different sampling methods and doing study on 32 year old persons in Thomson et al. study.

Unlike the present study, Hahnel et al. (2014) (21) reported that the prevalence of xerostomiawas16\% in their study on 68 subjects older than 60 years. The conflicting results of this study compared to the previous studies are probably related to variety in sample size and age of the patients.

The results of the present study showed that xerostomia is more common among women (39.8\%) compared to men (31.2\%). The results of the Pajukoski et al. study (10) as well as Silverman (22) and Nederfors et al. (23) studies were consistent with the results of the present study and the prevalence of this condition in women was higher than in men, but there was no relationship between these two variants (gender and xerostomia) in Orellana et al. (13), Thomson et al. (9) and Salako et al. (11) studies.

Considering the high prevalence of xerostomia among women, it seems that menopause and hormonal changes can be predisposing factors for xerostomia. The results of the recent study confirm this relation too. Other studies mentioned that mouth dryness often occurs in menopaused women but relation between these two variants is not clear now. It seems that hormonal changes in menopause and depression related to it can be predisposing factors for xerostomia development in women (24).

In our study, the prevalence of xerostomia was higher in persons older than 51 years, which is similar to Nederfors et al. (23) and Orellana et al. (13) studies. Predisposing factors of xerostomia in elderly individuals are dehydration, systemic disease involvement, taking more medications and salivary gland changes (7).

In the present study, $50 \%$ of the patients with mouth breathing had xerostomia. Similarly Narhi et al. (25) concluded that there is a close relationship between xerostomia and mouth breathing. Mouth breathing leads to decrease in oral mucosa wetness, which deteriorates the sensation of oral dryness but is not related to lower function of salivary glands. In the present study the highest rate of mouth dryness was reported in patients involved with neuro-psychological disorders; similarly in Thomson et al. study (9), psychologic disorders was a predisposing factor for xerostomia. According to the results of more studies, the use of tranquilizers and antidepressant drugs in psychotic patients is a predisposing factor that can cause deterioration and durability of the symptoms of xerostomia (10-12).
Over1500 drugs have been identified as having some xerogenic effects. Among them antihistamines, antidepressant and diuretics with different mechanism can cause xerostomia (7). In the present study, antihistamines and bronchodilators more than other pharmaceutical groups can cause xerostomia. Orellana (13) and Murray Thomson et al. (9) achieved similar results too. Although in our study the influence of bronchodilators on xerostomia was more noticeable, other studies often have pointed that tranquilizers and antidepressants caused xerostomia $(7,10,16)$. Analgesics had a minimum effect in xerostomia occurrence in our study; however, the results of Thomson et al. study (9) showed that an analgesic's role in xerostomia occurrence was significant.

In general, in our study $63.2 \%$ of the patients who taking one or two drugs had xerostomia, which is similar to Dawidson et al. study (26).

Some systemic diseases are a predisposing factor for dry mouth development. In this study $66.7 \%$ of the diabetic patients had xerostomia. Sreebny et al. (16) study reported that $40 \%-80 \%$ of diabetic patients involved with xerostomia. Diabetes can cause xerostomia through effect on salivary glands function and decreasing salivary secretion.

In our study the prevalence of xerostomia in patients with psychotic and cardiovascular disease was higher than in other subjects. This finding is similar to Thomson's results. Psychological disorders decrease saliva secretion and mucosal moisture, which fortify mouth dryness (9).

In the present study, $64 \%$ of the patients with breathing disorders were affected by xerostomia, which is in agreement with Pajukoski et al. (10) results.

In this study, the prevalence rates of xerostomia among cigarette smokers (52.2\%) and hookah users (61.3\%) were more than snuff users (32.2\%) and opium takers (33.3\%).

Porter and Borges et al. $(27,28)$ concluded that cigarette and tobacco use can be considered as two important factors for xerostomia occurrence.

Although the sample size is small in the present study, due to the different strata of society including young people and the elderly, healthy people and persons with the systemic disease, attending to the dental school for their dental problems, the results of this study can be approximately extended to the entire community.

\subsection{Conclusion}

It seems that xerostomia is more common in females and elderly people. The prevalence of xerostomia is relatively high and systemic diseases (especially psychoneurological disorders) medication used (especially antihistamines and bronchodilators), age and gender were the related factors with xerostomia. Since in some cases there was no predisposing factor for xerostomia, it is necessary 
that further studies be performed in this field to survey other possible factors. All of the groups with high likelihood of dry mouth should be investigated, at regular intervals and screened for early signs of dry mouth, for treating and prevention from disease progression.

\section{Acknowledgments}

The authors would like to kindly appreciate the vicechancellor for research, Zahedan University of Medical Sciences, for the financial support. The results described in this paper are a part of a (D.D.S) student thesis proposal.

\section{References}

1. Abbatecola AM, Maggi S, Paolisso G. New approaches to treating type 2 diabetes mellitus in the elderly: role of incretin therapies. Drugs Aging. 2008;25(11):913-25. [PubMed: 18947259].

2. de Almeida Pdel V, Gregio AM, Machado MA, de Lima AA, Azevedo LR. Saliva composition and functions: a comprehensive review.JContemp Dent Pract. 2008;9(3):72-80. [PubMed: 18335122].

3. Rad M, Chamani G, Shahravan A, Hedayati N, Alizadeh F. Survey of prevalence of xerostomia in a population of Kerman, Iran, attending medical and dental clinics. J Oral Health Oral Epidemiol. 2013;2(1):2834

4. Navazesh M, A. D. A. Council on Scientific Affairs, Division of S. How can oral health care providers determine if patients have dry mouth? JAm Dent Assoc. 2003;134(5):613-20. [PubMed:12785497] quiz 633.

5. IDF Diabetes Atlas . International Diabetes Federation. 4 ed. Brussels: IFD; 2009.

6. De Morais EF, De Paiva Macedo AR, Da Silva Lira JA. Factors related to dry mouth and low salivary flow rates in diabetic elderly: a systematic literature review. Bras Geriatr Gerontol Rev. 2014;17(2):417-23.

7. Martin S, Greenberg M. Burket's Oral medicine diagnosis and treatment. 12 ed. Spain: BC Decker Inc; 2014. pp. 191-206.

8. Ghavam M. Oral lesions following radiation therapy and their preven tive considerations. J Dent Med Tehran Univ Med Sci. 2001;27(14):60-7.

9. Murray Thomson W, Poulton R, Mark Broadbent J, Al-Kubaisy S. Xerostomia and medications among 32-year-olds. Acta Odontol Scand. 2006;64(4):249-54. [PubMed: 16829502].

10. Pajukoski H, Meurman JH, Halonen P, Sulkava R. Prevalence of subjective dry mouth and burning mouth in hospitalized elderly patients and outpatients in relation to saliva, medication, and systemic diseases. Oral Surg Oral Med Oral Pathol Oral Radiol Endod. 2001;92(6):6419. [PubMed: 11740482].

11. Salako N, Farsi J. Prevalence of self reported xerostomia in a cross sectional population in the western province of Saudi Arabia. Saudi Den J. . 2005;17(1):;7(1):29-33.

12. Pujol T, Coma M, Pujol M, Postigo P. [Prevalence of xerostomia in the general population]. Aten Primaria. 1998;21(4):225-8. [PubMed: 9607250].
13. Orellana MF, Lagravere MO, Boychuk DG, Major PW, Flores-Mir C. Prevalence of xerostomia in population-based samples: a systematic review. J Public Health Dent. 2006;66(2):152-8. [PubMed: 16711637].

14. Baharvand M, Hemmati F. Frequency of subjective dry mouth and burning mouth syndrome in elder residents of sanitariums in Tehran. J Islamic Society Dent. 2005;18(2):86-91.

15. Wong DT. Salivary Diagnostics: Amazing as it might seem, doctors can detect and monitor diseases using molecules found in a sample of spit. Am Sci. 2008;96(1):37-43. [PubMed: 19750202].

16. Sreebny LM, Schwartz SS. A reference guide to drugs and dry mouth2nd edition. Gerodontology. 1997;14(1):33-47. [PubMed: 9610301].

17. Mirjalili N, Karbassi MA, Gazerani M. Management of xerostomia in patients with compromised health status - A Clinical Study. Int J Dent Clin. 2015;7(1):1-4.

18. Wilczynska-Borawska M, Baginska J, Borawski J. Is xerostomia a risk factor for cardiovascular morbidity and mortality in maintenance hemodialysis patients? Med Hypotheses. 2012;79(4):544-8. doi: 10.1016/j.mehy.2012.07.016. [PubMed: 22874451]

19. Turner MD, Ship JA. Dry mouth and its effects on the oral health of elderly people. J Am Dent Assoc. 2007;138 Suppl:15S-20S. [PubMed: 17761841].

20. Kaur M, Himadi E, Chi DL. Prevalence of xerostomia in an adolescent inpatient psychiatric clinic: a preliminary study. Spec Care Dentist. 2016;36(2):60-5. doi: 10.1111/scd.12154. [PubMed: 26687928].

21. Hahnel S, Schwarz S, Zeman F, Schafer L, Behr M. Prevalence of xerostomia and hyposalivation and their association with quality of life in elderly patients in dependence on dental status and prosthetic rehabilitation: a pilot study. J Dent. 2014;42(6):664-70. doi: 10.1016/j.jdent.2014.03.003. [PubMed: 24632475].

22. Silverman J, Eversole B, Truelove M. Essentials of oral medicine. Hamilton: Be Decker Inc; 2002. pp. 260-71.

23. Nederfors T, Isaksson R, Mornstad H, Dahlof C. Prevalence of perceived symptoms of dry mouth in an adult Swedish populationrelation to age, sex and pharmacotherapy. Community Dent Oral Epidemiol. 1997;25(3):211-6. [PubMed: 9192149].

24. Borhan Mojabi K, Esfahani M, Jahani Hashemi H. Evaluation of un stimulated salivary flow rate and oral symptoms in menopausal women. J Dent Med Tehran Univ Med Sci. 2007;4(3):103-6.

25. Narhi TO, Meurman JH, Ainamo A. Xerostomia and hyposalivation: causes, consequences and treatment in the elderly. Drugs Aging. 1999;15(2):103-16. [PubMed: 10495070].

26. Dawidson I, Angmar-Mansson B, Blom M, Theodorsson E, Lundeberg T. Sensory stimulation (acupuncture) increases the release of calcitonin gene-related peptide in the saliva of xerostomia sufferers. Neuropeptides. 1999;33(3):244-50. doi: 10.1054/npep.1999.0759. [PubMed: 10657499].

27. Porter SR, Scully C, Hegarty AM. An update of the etiology and management of xerostomia. Oral Surg Oral Med Oral Pathol Oral Radiol Endod. 2004;97(1):28-46. doi: 10.1016/S1079210403005572. [PubMed: 14716254].

28. Borges BC, Fulco GM, Souza AJ, de Lima KC. Xerostomia and hyposalivation: a preliminary report of their prevalence and associated factors in Brazilian elderly diabetic patients. Oral Health Prev Dent. 2010;8(2):153-8. [PubMed: 20589249]. 